\title{
Surgical Pain After Transobturator and Retropubic Midurethral Sling Placement
}

\author{
Tonya N. Thomas, MD, Lauren N. Siff, MD, J. Eric Jelovsek, MD, MMEd, and Matthew Barber, MD, MHS
}

OBJECTIVE: To compare prevalence and severity of any surgical pain between transobturator and retropubic slings; secondary aims were to compare pain at anatomic locations, pain medication use, and pain resolution between transobturator and retropubic slings and to compare pain between types of transobturator slings.

METHODS: This is a secondary analysis of the Trial of Mid-Urethral Slings, which compared retropubic and transobturator sling outcomes and included 597 participants from 2006 to 2008. Postoperative assessments included body maps, visual analog scales, Surgical Pain Scales, and medication inventories for 30 days, at 6 weeks, and 6, 12, and 24 months. Postoperative pain prevalence and severity were compared. Mixed models compared pain resolution and severity over time. Regression models compared pain prevalence and severity between types of transobturator slings. Eighty percent power was provided for the primary outcome pain prevalence and $95 \%$ power was provided for the primary outcome pain severity.

From the Obstetrics, Gynecology and Women's Health Institute, Cleveland Clinic, Cleveland, Ohio.

The Trial of Mid-Urethral Slings was conducted by the Urinary Incontinence Treatment Network and supported by the National Institute of Diabetes and Digestive and Kidney Diseases. The data from the Trial of Mid-Urethral Slings reported here were supplied by the National Institute of Diabetes and Digestive and Kidney Diseases Central Repositories. This manuscript was not prepared in collaboration with investigators of the Trial of Mid-Urethral Slings and does not necessarily reflect the opinions or viewes of the Urinary Incontinence Treatment Network, the National Institute of Diabetes and Digestive and Kidney Diseases Central Repositories, or the National Institute of Diabetes and Digestive and Kidney Diseases.

Presented at the American Urogynecologic Society Pelvic Floor Disorders Week 2016, September 27-October 1, 2016, Denver, Colorado.

Each author has indicated that he or she has met the journal's requirements for authorship.

Corresponding author: Tonya N. Thomas, MD, Cleveland Clinic, 9500 Euclid Avenue A81, Cleveland, OH 44195; email: thomast8@ccforg.

\section{Financial Disclosure}

The authors did not report any potential conflicts of interest.

(C) 2017 by The American College of Obstetricians and Gynecologists. Published by Wolters Kluwer Health, Inc. All rights reserved.

ISSN: 0029-7844/17
RESULTS: Postoperative prevalence of any surgical pain, pain severity, and pain medication was not different between retropubic and transobturator slings. Retropubic sling was associated with greater prevalence of suprapubic pain at 2 weeks (proportion difference 10.6\%; 95\% confidence interval $[\mathrm{CI}] 4.6-16.4 \%$; $P<001$ ). Transobturator sling was associated with greater prevalence of groin pain at 2 weeks (proportion difference $12.0 \%$; 95\% Cl 7.1-16.8\%; $P<001)$. There was no difference in pain resolution (odds ratio [OR] $1.11,95 \% \mathrm{Cl}$ 0.88-1.40; $P=.38$ ). Between types of transobturator slings, the odds of surgical pain were similar at 2 (OR $2.39,95 \%$ $\mathrm{Cl} 0.51-11.31 ; P=.27$ ) and 6 weeks (OR $0.46,95 \% \mathrm{Cl} 0.02$ 9.20; $P=.61)$.

CONCLUSION: Transobturator and retropubic slings are associated with low prevalence of any surgical pain. Transobturator sling was associated with greater prevalence of groin pain at 2 weeks, and retropubic sling was associated with greater prevalence of suprapubic pain at 2 weeks. Surgical pain resolved quickly in both groups.

(Obstet Gynecol 2017;130:118-25)

DOI: 10.1097/AOG.0000000000002068

$\mathrm{T}$ he midurethral sling is a common, safe, and effective surgery for the treatment of stress urinary incontinence. ${ }^{1-3}$ Two surgical approaches exist, retropubic and transobturator. ${ }^{4,5}$ Risks of the retropubic approach include voiding dysfunction, bladder injury, and vascular injury. ${ }^{2}$ The transobturator approach avoids the risks associated with retropubic passage of the trocars; however, a recent Cochrane review reports higher rates of groin pain. ${ }^{6}$ The included studies utilized heterogeneous terms to define pain and pain location (eg, groin pain, thigh pain, wound discomfort, inner thigh discomfort, and groin pain during vaginal palpation). ${ }^{7-12}$

The largest prospective randomized trial comparing retropubic and transobturator midurethral slings was the Trial of Mid-Urethral Slings. ${ }^{2}$ Selfadministered postoperative pain diaries and pain assessments were collected at regular intervals for up to 

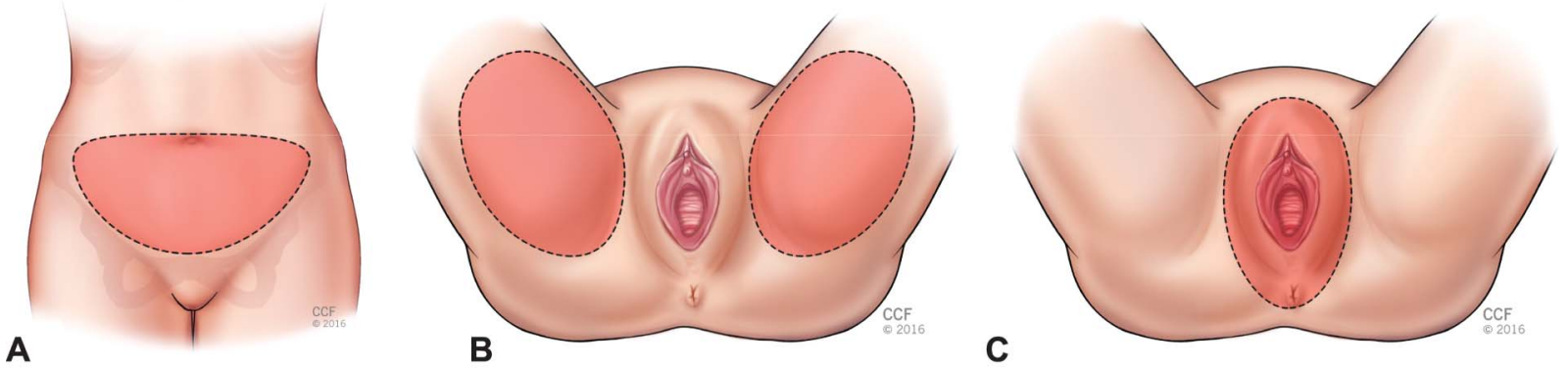

Fig. 1. Defined anatomic locations of the suprapubic area (A), groin (B), and vulva (C). Reprinted with permission, Cleveland Clinic Center for Medical Art \& Photography (C) 2016. All rights reserved.

Thomas. Surgical Pain After Midurethral Sling. Obstet Gynecol 2017.

2 years. ${ }^{13}$ The primary Trial of Mid-Urethral Slings defined bothersome pain at or beyond 6 weeks postsurgery by fulfillment of strict criteria, which may not have captured all clinically relevant pain. ${ }^{14}$ Results showed self-reported pain at or beyond 6 weeks was low (retropubic 2.3\%; transobturator 2.0\%; $P=.79$ ). ${ }^{2}$

Table 1. Definitions of Pain Presence, Absence, and Severity

\begin{tabular}{|c|c|}
\hline Outcome & Definition \\
\hline $\begin{array}{l}\text { Presence of any surgical } \\
\text { pain* }\end{array}$ & $\begin{array}{l}\text { Affirmative response to "Have you } \\
\text { had any pain within the last } 24 \mathrm{~h} \\
\text { as a result of your incontinence } \\
\text { operation?" }\end{array}$ \\
\hline $\begin{array}{l}\text { Presence of suprapubic, } \\
\text { groin, and vulvar pain }\end{array}$ & $\begin{array}{l}\text { Affirmative response to "Have you } \\
\text { had [suprapubic, groin, vulvar] } \\
\text { pain within the last } 24 \text { h as } \\
\text { a result of your incontinence } \\
\text { operation?" } \\
\text { AND } \\
\text { A corresponding mark on the } \\
\text { body map within or on the } \\
\text { border of the defined anatomic } \\
\text { location }\end{array}$ \\
\hline $\begin{array}{l}\text { Absence of any surgical } \\
\text { pain* }\end{array}$ & $\begin{array}{l}\text { Negative response to the question } \\
\text { "Have you had any pain within } \\
\text { the last } 24 \text { h as a result of your } \\
\text { incontinence operation?" } \\
\text { AND } \\
\text { No pain medication use for pain } \\
\text { related to the incontinence } \\
\text { operation (2-wk, 6-wk, and } \\
6 \text {-mo assessments only) }\end{array}$ \\
\hline $\begin{array}{l}\text { Severity of any surgical } \\
\text { pain* }\end{array}$ & $\begin{array}{l}\text { Surgical Pain Scales score }(0-150) \\
\text { for "How much pain did you } \\
\text { have during your daily activities?" }\end{array}$ \\
\hline $\begin{array}{l}\text { Severity of suprapubic, } \\
\text { groin, and vulvar pain }\end{array}$ & $\begin{array}{l}\text { Visual analog scale score }(0-150) \\
\text { corresponding to the defined } \\
\text { anatomic location }\end{array}$ \\
\hline
\end{tabular}

* Any pain related to the incontinence operation.
Anatomic locations of pain included suprapubic pain and groin pain (retropubic $\mathrm{n}=3$; transobturator $\mathrm{n}=2$ ), suprapubic pain only (retropubic $\mathrm{n}=3$; transobturator $\mathrm{n}=3$ ), and other pain (retropubic $\mathrm{n}=1$; transobturator $n=2) .{ }^{14}$

For the current study, a secondary analysis of the Trial of Mid-Urethral Slings was performed using the clearly defined and standardized questionnaires, body maps, and pain severity scales to report postoperative pain specific to retropubic and transobturator midurethral sling procedures using clinically relevant definitions. We hypothesized there would be no difference in the prevalence of any surgical pain or pain severity with daily activities between the retropubic and transobturator midurethral sling groups.

\section{MATERIALS AND METHODS}

The current study is a secondary analysis of the Trial of Mid-Urethral Slings using the publically available data set. The study was approved by the institutional review board at Cleveland Clinic. The primary aim was to compare the prevalence of any surgical pain (any pain related to the incontinence operation) and pain severity (Surgical Pain Scales score assessing pain with daily activities) between the Trial of MidUrethral Slings participants who received the transobturator midurethral sling and participants who received the retropubic midurethral sling at 2 and 6 weeks postoperatively. We hypothesized there would be no difference in the prevalence of any surgical pain or pain severity. Secondary aims were to compare the prevalence of any surgical pain and pain severity with daily activities at 6 months; the prevalence and severity of groin, suprapubic, and vulvar pain and pain medication use for pain resulting from the incontinence operation at 2 weeks, 6 weeks, and 6 months; the resolution of any surgical pain; and the prevalence and severity of surgical pain between

Copyright $(\subset$ by The American College of Obstetricians and Gynecologists. Published by Wolters Kluwer Health, Inc. Unauthorized reproduction of this article is prohibited. 
Table 2. Baseline Pain Characteristics of the Retropubic and Transobturator Midurethral Sling Groups

\begin{tabular}{|c|c|c|c|c|}
\hline Baseline Variable & Total $(\mathrm{N}=597)$ & Retropubic $(\mathrm{n}=298)$ & Transobturator $(n=299)$ & $P$ \\
\hline Suprapubic pain & $114(19.1)$ & $56(18.8)$ & $58(19.4)$ & $.85^{*}$ \\
\hline Groin pain & $15(2.5)$ & $7(2.3)$ & $8(2.7)$ & $.80^{*}$ \\
\hline Vulvar pain & $27(4.5)$ & $16(5.4)$ & $11(3.7)$ & $.32 *$ \\
\hline Pain medication use & $224(37.5)$ & $115(38.6)$ & $109(36.5)$ & $.59^{*}$ \\
\hline Surgical Pain Scales score (daily activities) ${ }^{+}$ & $9.0(0-148)$ & $11.5(0-145)$ & $8.0(0-148)$ & $.71^{\ddagger}$ \\
\hline
\end{tabular}

Data are $\mathrm{n}(\%)$ or median (range) unless otherwise specified.

* Pearson $x^{2}$ test.

+ "How much pain did you have during your daily activities?" (Visual analog scale range 0-150 mm).

${ }^{\ddagger}$ Kruskal-Wallis test.

participants who received different types of transobturator slings (inside-out or outside-in, defined by the direction the trocar is passed through the obturator foramen). ${ }^{13}$

The design, methodology, and results of the primary Trial of Mid-Urethral Slings have been previously published. ${ }^{2,13,14}$ In brief, the Trial of Mid-Urethral Slings was a prospective multicenter randomized equivalence trial of 597 participants with stress urinary incontinence randomized to either a transobturator or retropubic midurethral sling between April 2006 and June 2008 to compare the 12-month efficacy and safety with the primary outcome of objective and subjective treatment success. ${ }^{2}$ Results showed equivalence in the rates of objective treatment success. ${ }^{2}$ Surgeons preselected which transobturator midurethral sling (inside-out or outside-in) they would use during the trial, must have performed five of each type of midurethral sling, and must have been observed performing the standardized key components of the procedures by their primary investigators. ${ }^{13}$ Participants undergoing current evaluation or treatment for chronic pelvic pain were excluded. All 597 participants who underwent surgery were included in the current analysis.
All participants in the Trial of Mid-Urethral Slings kept daily pain diaries for 15 days after surgery and up to 30 days if they continued to report pain. Additional assessments using self-administered questionnaires occurred at 2 and 6 weeks and 6,12 , and 24 months after surgery. The assessments included standardized questions, body diagrams, visual analog scales specific to each anatomic location, the McCarthy Surgical Pain Scales, which assess the sensory and affective components of operative pain, and a pain medication inventory. ${ }^{15}$ The assessments were completed at each time point. The daily pain diary did not include the Surgical Pain Scales or medication inventory if no pain resulting from the incontinence operation was reported that day.

Each anatomic location (eg, lower abdomen, inner thigh, inside the vagina, outside the vagina but inside the thigh crease, lower back, anterior legs, posterior legs, or buttocks) was strictly defined and described to the participants using standardized terminology and body maps at a teaching visit. For the current study, we defined the lower abdomen as "suprapubic," the inner thigh as "groin," and the area outside the vagina but inside the thigh crease as "vulva" (Fig. 1A-C). Given that the strict definition

Table 3. Pain Prevalence in the Retropubic and Transobturator Midurethral Sling Groups

$2 \mathrm{Wk}$

\begin{tabular}{lccc} 
& Transobturator $(\mathbf{n}=\mathbf{2 9 7})$ & Retropubic $(\mathbf{n}=291)$ & $\boldsymbol{P}^{*}$ \\
\cline { 2 - 4 } Prevalence & $94(31.6)(26.6-37.1)$ & $83(28.5)(23.6-34.0)$ & .41 \\
Any surgical pain $^{+}$ & $47(15.8)(12.1-20.4)$ & $42(14.4)(10.9-18.9)$ & .64 \\
Medication use $^{\ddagger}$ & $32(10.8)(7.7-14.8)$ & $62(21.4)(17.1-26.5)^{\|}$ & $<.001$ \\
Suprapubic pain & $49(16.5)(12.7-21.1)$ & $13(4.5)(2.6-7.5)$ & $<.001$ \\
Groin pain & $34(11.5)(8.3-15.6)^{\|}$ & $22(7.6)(5.1-11.2)^{\|}$ & .11 \\
Vulvar pain & & &
\end{tabular}

Data are $\mathrm{n}(\%)(95 \%$ confidence interval) unless otherwise specified.

* Pearson $x^{2}$ test.

${ }^{+}$Any pain related to the incontinence operation.

₹ Use of pain medication for pain resulting from the incontinence operation.

$\S$ Fisher exact test.

"Missing $\mathrm{n}=1$.

Copyright $\odot$ by The American College of Obstetricians and Gynecologists. Published by Wolters Kluwer Health, Inc. Unauthorized reproduction of this article is prohibited. 
of bothersome pain used in the primary Trial of MidUrethral Slings may have precluded the observation of some clinically relevant pain, the current study used broad definitions (Table 1) to determine the presence or absence of surgical pain using self-reported pain and the use of pain medications.

Baseline variables included in the current analysis were participating site, age, vaginal parity, race or ethnicity, marital status, education, prolapse stage, any hormone therapy use, current smoking status, prior surgery for urinary incontinence, prior treatment for urinary incontinence, prior prolapse surgery, subjective baseline pain prevalence (suprapubic, groin, and vulvar), pain medication use, and Surgical Pain Scales score assessing pain severity with daily activity.

All analyses were performed in SAS 9.4. Baseline characteristics, pain prevalence, and pain severity were compared between retropubic and transobturator groups at 2 weeks, 6 weeks, and 6 months after surgery using Pearson $\chi^{2}$ test or Fisher exact test for categorical measures and the Student $t$ test or KruskalWallis test for continuous measures, as appropriate. Generalized linear mixed models were performed for resolution of pain up to 6 weeks postoperatively, controlling for participating site and time, in which correlation within the same participant was adjusted. The data and models used were independently validated by a second statistician team. Multivariate logistic and linear regressions were performed to compare pain prevalence and severity between types of transobturator midurethral slings.

Given the fixed sample size of the Trial of MidUrethral Slings (298 patients in the retropubic arm and 299 patients in the transobturator arm) and assuming a baseline $25 \%$ prevalence of any surgical pain (any pain related to the incontinence operation) at 2 weeks and a $10 \%$ prevalence of any surgical pain at 6 weeks, the existing sample size provides greater than $80 \%$ power to detect a $10 \%$ difference in the prevalence of surgical pain with a significance level of .05. The existing sample size also provided greater than $95 \%$ power to detect a minimally important difference of $33 \mathrm{~mm}$ in the mean rating on the 150-mm Surgical Pain Scales question assessing pain during normal activities. ${ }^{15}$

To correct for type I error resulting from multiple comparisons, a Bonferroni correction was calculated separately for the primary and secondary outcomes. A significance level of .0125 was considered for the primary outcomes prevalence of any surgical pain at 2 and 6 weeks and pain severity with daily activities at 2 and 6 weeks (four comparisons). A significance level of .0023 was considered for the secondary outcomes prevalence of any surgical pain and pain severity with daily activities at 6 months; prevalence and severity of groin, suprapubic, and vulvar pain; and pain medication use for pain resulting from the incontinence operation at 2 weeks, 6 weeks, and 6 months (22 comparisons). All baseline characteristics were compared at a significance level of .05.

\section{RESULTS}

Five hundred ninety-seven participants in the Trial of Mid-Urethral Slings were randomized and underwent midurethral sling surgery; 299 received a transobturator midurethral sling and 298 received a retropubic midurethral sling. Among the transobturator group, 161 received the inside-out midurethral sling and 138 received the outside-in midurethral sling. One participant assigned to the transobturator group received a retropubic midurethral sling and one participant assigned to the retropubic group received the outsidein transobturator midurethral sling. Baseline demographic and clinical characteristics of Trial of Mid-Urethral Slings participants have been reported

\begin{tabular}{|c|c|c|c|c|c|}
\hline \multicolumn{3}{|c|}{$6 \mathrm{Wk}$} & \multicolumn{3}{|c|}{$6 \mathrm{Mo}$} \\
\hline Transobturator $(n=296)$ & Retropubic $(n=293)$ & $P^{*}$ & Transobturator $(n=276)$ & Retropubic $(n=274)$ & $P$ \\
\hline $33(11.1)(8.0-15.2)$ & $24(8.2)(5.6-11.9)$ & .22 & $14(5.1)(3.0-8.3)$ & $10(3.6)(2.0-6.6)$ & $.41^{*}$ \\
\hline $16(5.4)(3.4-8.6)$ & $10(3.4)(1.9-6.2)$ & .24 & $3(1.1)(0.4-3.1)$ & $3(1.1)(0.4-3.2)$ & $.99^{\S}$ \\
\hline $15(5.1)(3.1-8.2)^{\|}$ & $14(4.8)(2.9-7.9)$ & .86 & $6(2.2)(1.0-4.7)$ & $5(1.8)(0.8-4.2)$ & $.77^{*}$ \\
\hline $10(3.4)(1.8-6.1)$ & $1(0.3)(0.1-1.9)$ & .006 & $3(1.1)(0.4-3.1)$ & $2(0.7)(0.2-2.6)$ & $.99^{\S}$ \\
\hline $7(2.4)(1.2-4.8)$ & $5(1.7)(0.7-3.9)$ & .57 & $1(0.4)(0.1-2.0)^{\mid \|}$ & 0 & $.99^{\S}$ \\
\hline
\end{tabular}

Copyright $(\odot$ by The American College of Obstetricians and Gynecologists. Published by Wolters Kluwer Health, Inc. Unauthorized reproduction of this article is prohibited. 
$2 \mathrm{Wk}$

\begin{tabular}{llll} 
& & Transobturator & Retropubic \\
\hline Suprapubic $^{\dagger}$ & $32 ; 19(2-150)$ & $62 ; 15(1-131)$ & $P^{*}$ \\
Groin $^{+}$ & $49 ; 18(0-106)$ & $13 ; 47(3-113)^{\ddagger}$ & .52 \\
Vulva $^{\dagger}$ & $34 ; 12(2-84)^{\ddagger}$ & $22 ; 30(4-143)$ & .07 \\
Surgical Pain Scales score (daily activity) $^{\S}$ & $94 ; 16(0-150)$ & $83 ; 14(0-145)$ & .01 \\
\hline
\end{tabular}

Data are $\mathrm{n}$; median score (range).

Only those participants reporting pain provided severity score data.

* Student $t$ test.

+ Visual analog scale range 1-150 mm.

* Severity score data missing for 1 patient.

$\S$ "How much pain did you have during your daily activities?" (visual analog scale range 0-150 mm).

previously. ${ }^{2,14}$ Baseline pain characteristics of retropubic and transobturator participants are shown in Table 2. There were no baseline differences between retropubic and transobturator groups including baseline prevalence of suprapubic pain, groin pain, or vulvar pain; the use of pain medications; or Surgical Pain Scales score assessing pain severity with daily activities.

There was no difference between retropubic and transobturator groups in the prevalence of any surgical pain, the severity of pain with daily activities, or pain medication use for pain related to the incontinence operation at 2 weeks, 6 weeks, or 6 months (Tables 3 and 4). Suprapubic pain was more prevalent in the retropubic group at 2 weeks (transobturator $\mathrm{n}=32[10.8 \%], 95 \%$ confidence interval $[\mathrm{CI}]$ $7.7-14.8 \%$; retropubic $\mathrm{n}=62$ [21.4\%], 95\% CI $17.1-$ $26.5 \% ; P<.001)$. The proportion difference in the prevalence of suprapubic pain at 2 weeks between transobturator and retropubic groups was $10.6 \%$ (95\% CI $4.6-16.4 \% ; P<.001)$. Groin pain was more prevalent in the transobturator group at 2 weeks (transobturator $\mathrm{n}=49$ [16.5\%], 95\% CI 12.7-21.1\%; retropubic $\mathrm{n}=13[4.5 \%], 95 \%$ CI $2.6-7.5 \% ; P<.001)$ with a proportion difference in the prevalence of groin pain between transobturator and retropubic groups of $12.0 \%$ (95\% CI $7.1-16.8 \% ; P<.001)$. At 6 weeks, the transobturator group appeared to be associated with a greater prevalence of groin pain (transobturator $\mathrm{n}=10 \quad[3.4 \%], 95 \%$ CI $1.8-6.1 \%$; retropubic $\mathrm{n}=1$ [0.3\%], 95\% CI $0.1-1.9 \% ; P=.006)$ with a proportion difference in the prevalence of groin pain between transobturator and retropubic groups of 3.0\% (95\% CI $0.7-5.3 \% ; P=.01)$; however, with Bonferroni correction, this difference was not considered significant. There was no difference in prevalence of groin pain at 6 months (transobturator $\mathrm{n}=3[1.1 \%], 95 \%$ CI $0.4-$ $3.1 \%$; retropubic $\mathrm{n}=2[0.7 \%], 95 \%$ CI $0.2-2.6 \%$;
$P=.99)$. There was no difference in the prevalence of vulvar pain at 2 weeks, 6 weeks, or 6 months. Pain severity scores at each anatomic location did not differ between groups (Table 4). At 12 months, five participants in the transobturator group and three participants in the retropubic group reported any pain related to the incontinence operation. At 24 months, seven participants in the transobturator group and four participants in the retropubic group reported any pain related to the incontinence operation.

There was no significant difference in resolution of any surgical pain up to 6 weeks after surgery when comparing the retropubic and transobturator groups after adjusting for participating site and time (odds ratio [OR] 1.11, 95\% CI 0.88-1.40; $P=.38$; Fig. 2A). The odds of pain resolution increased by $12 \%$ per day up to 6 weeks when controlling for midurethral sling type and participating site (OR 1.12, 95\% CI $1.11-1.13 ; P<.001)$. Seventy percent were pain-free by 2 weeks and $90 \%$ by 6 weeks. There was no significant difference between groups in the Surgical Pain Scales score assessing daily activity for all participants (score imputed as 0 for participants without surgical pain) or for participants who reported the presence of pain $(P=.84)$ after adjusting for site and time (Fig. 2B and C).

In the subgroup analysis of transobturator midurethral sling type (inside-out or outside-in), baseline differences were observed in participating site, age, hormone therapy use, previous prolapse surgery, and baseline Surgical Pain Scales score assessing daily activities (Table 5). No differences were observed in baseline prevalence of suprapubic, groin, or vulvar pain or the use of pain medications. The odds of any surgical pain for the outside-in group compared with the inside-out group were not different at 2 weeks (OR 2.39, 95\% CI 0.51-11.31; $P=.27$ ) or 6 weeks (OR $0.46,95 \%$ CI $0.02-9.20 ; P=.61)$ after adjusting for

Copyright $\odot$ by The American College of Obstetricians and Gynecologists. Published by Wolters Kluwer Health, Inc. Unauthorized reproduction of this article is prohibited. 


\begin{tabular}{|c|c|c|c|c|c|}
\hline \multicolumn{3}{|c|}{$6 \mathrm{Wk}$} & \multicolumn{3}{|c|}{$6 \mathrm{Mo}$} \\
\hline Transobturator & Retropubic & $P^{*}$ & Transobturator & Retropubic & $P^{*}$ \\
\hline $15 ; 26(6-94)^{\ddagger}$ & $14 ; 22(2-140)$ & .48 & $6 ; 51(3-112)$ & $5 ; 52(13-148)$ & .67 \\
\hline $10 ; 16(2-86)$ & $1 ; 31$ & .95 & $3 ; 15$ (3-149) & $2 ; 93(53-132)$ & .62 \\
\hline $7 ; 25(4-75)$ & $5 ; 39(8-100)^{\ddagger}$ & .35 & $1 ; 2$ & 0 & - \\
\hline $33 ; 10(0-133)$ & $24 ; 10(0-133)$ & .63 & $14 ; 12(0-133)$ & $10 ; 24(0-125)$ & .58 \\
\hline
\end{tabular}

baseline differences. There were too few observations to compare severity of pain between subgroups.

\section{DISCUSSION}

This secondary analysis of the Trial of Mid-Urethral Slings using clinically relevant definitions for pain prevalence and severity after transobturator or retropubic midurethral sling placement showed both groups were associated with low and similar prevalence of any surgical pain (any pain related to the incontinence operation) and severity of pain with daily activities at 2 weeks, 6 weeks, and 6 months, supporting our hypothesis. Surgical pain after midurethral sling surgery was completely resolved in approximately $70 \%$ by 2 weeks and $90 \%$ by 6 weeks with the odds of pain resolution increasing by $12 \%$ each day up to 6 weeks after surgery. Retropubic midurethral sling surgery was associated with greater prevalence of suprapubic pain at 2 weeks and transobturator midurethral sling was associated with greater prevalence of groin pain at 2 weeks. For both, the rate was low and there were no statistically significant or clinically relevant differences by 6 weeks. In addition, the use of pain medication was low in both groups. By 6 weeks, only $5.4 \%$ and $3.4 \%$ of participants in the transobturator and retropubic groups, respectively, were using medication (narcotic and nonnarcotic) for pain related to their incontinence operation.

Given that the Trial of Mid-Urethral Slings showed equivalent rates of objective treatment success between transobturator and retropubic midurethral slings, it is essential to compare adverse events between these two techniques. ${ }^{2}$ The retropubic midurethral sling was associated with more serious adverse events including bladder injury, voiding dysfunction, and mesh exposure. ${ }^{2}$ Considering pain an adverse event, the Trial of Mid-Urethral Slings showed strictly defined self-reported pain at or beyond 6 weeks was low and similar between groups. ${ }^{2,14}$ Other studies have reported higher rates of groin pain with transobturator midurethral sling placement. ${ }^{7,10,11}$

The current study sought to compare pain prevalence and severity after transobturator or retropubic midurethral sling surgery using clinically relevant definitions and standardized, validated measures. This may explain some of the differences between our findings and those from a systematic review or meta-analysis, in which the definitions and measures of pain may be heterogeneous. For
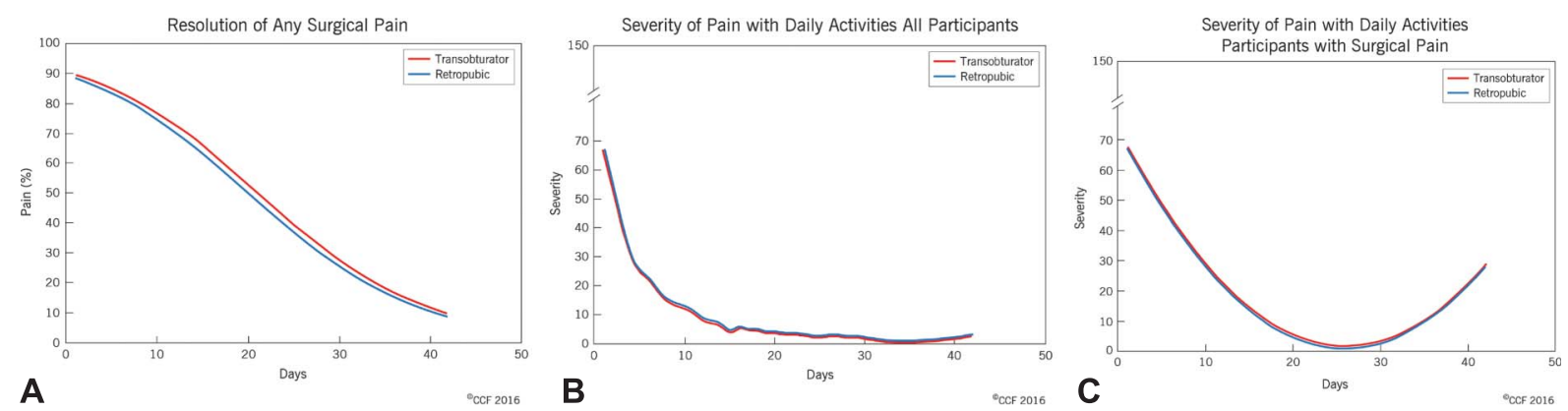

Fig. 2. A. Resolution of any surgical pain (any pain related to the incontinence operation). Percentage of participants with pain is depicted over time up to 6 weeks postoperatively. B. Severity of pain with daily activities (all participants, score imputed as 0 for participants without surgical pain). C. Severity of pain with daily activities (participants with surgical pain). Severity is the Surgical Pain Scales score assessing pain with daily activity (150-mm visual analog scale). Change in pain severity score is depicted over time up to 6 weeks postoperatively. Reprinted with permission, Cleveland Clinic Center for Medical Art \& Photography (C) 2016. All rights reserved.

Thomas. Surgical Pain After Midurethral Sling. Obstet Gynecol 2017.

Copyright $($ by The American College of Obstetricians and Gynecologists. Published by Wolters Kluwer Health, Inc. Unauthorized reproduction of this article is prohibited. 
Table 5. Baseline Characteristics of the Inside-Out and Outside-In Transobturator Midurethral Sling Subgroups

\begin{tabular}{|c|c|c|c|c|}
\hline Baseline Variable & Total $(n=299)^{*}$ & Inside-out $(n=161)$ & Outside-in $(n=138)$ & $P$ \\
\hline Age, median (range) & $51.6(27.3-86.6)$ & $50.5(27.3-86.6)$ & $54.3(31.1-81.3)$ & $.02^{+}$ \\
\hline Hormone therapy & & & & $.002^{\ddagger}$ \\
\hline No & $116(39.1)$ & $68(42.2)$ & $48(35.3)$ & \\
\hline Yes & $90(30.3)$ & $35(21.7)$ & $55(40.4)$ & \\
\hline Premenopausal & $91(30.6)$ & $58(36.0)$ & $33(24.3)$ & \\
\hline Previous prolapse surgery & $10(3.4)$ & $2(1.2)$ & $8(5.9)$ & $.03^{\neq}$ \\
\hline Suprapubic pain & $59(19.7)$ & $37(23.0)$ & $22(15.9)$ & $.13^{\ddagger}$ \\
\hline Groin pain & $8(2.7)$ & $4(2.5)$ & $4(2.9)$ & $.99^{\ddagger}$ \\
\hline Vulvar pain & $12(4.0)$ & $8(5.0)$ & $4(2.9)$ & $.36^{\ddagger}$ \\
\hline Pain medication use & $109(36.5)$ & $54(33.5)$ & 55 (39.9) & $.26^{\neq}$ \\
\hline Surgical Pain Scales score (daily activities) ${ }^{\S}$ & $8.0(0-148)$ & $4.0(0-148)$ & $17.5(0-128)$ & $.02^{+}$ \\
\hline
\end{tabular}

Data are median (range) or $\mathrm{n}(\%)$ unless otherwise specified.

* Differences in column data compared with Table 2 are the result of per-protocol subgroup analysis.

${ }^{+}$Kruskal-Wallis test.

* Pearson $\chi^{2}$ test.

$\S$ "How much pain did you have during your daily activities?" (visual analog scale range 0-150 mm).

example, a recent Cochrane review determined that the rate of groin pain in women who underwent transobturator midurethral sling surgery was $6.4 \%$ compared with $1.3 \%$ for retropubic midurethral sling (relative risk 4.12, 95\% CI 2.71-6.27); however, groin pain, thigh pain, wound discomfort, inner thigh discomfort, and groin pain during vaginal palpation are all various terms used to describe pain after midurethral sling surgery, and many of these studies did not individually separate these terms nor did they collect multiple different assessments of pain. ${ }^{6-12}$

Strengths of our study include the large, randomized, prospective, multicenter Trial of MidUrethral Slings database used for this secondary analysis and the use of standardized questionnaires and strictly defined anatomic areas that were described to participants using standardized terminology and body maps at frequent intervals to assess postsurgical pain. The inclusion of the use of any pain medication for pain resulting from the incontinence operation in the definition of absence of surgical pain allowed for a clinically relevant assessment of the resolution of pain.

Limitations of the study include the lack of data on daily pain medication use during the daily pain diaries for those participants who did not report pain; however, medication use was captured at the 2-week, 6-week, and 6-month assessments. Additionally, there were too few observations to make a reliable assumption about the association between pain severity and type of transobturator midurethral sling; however, the prevalence of pain did not appear to differ. In addition, although multiple statistical comparisons may lead to some spurious results, correction was made to reduce the risk of type I error in the current analysis.

The current study may be used by health care providers to counsel patients considering midurethral sling surgery for the treatment of stress urinary incontinence on the anticipated prevalence and course of resolution of surgical pain after transobturator in comparison with retropubic midurethral sling surgery. Overall, surgical pain after midurethral sling surgery is low, similar between groups, and resolves quickly. Although previous studies have reported groin pain to be greater with the transobturator midurethral sling, the current study showed groin pain is low and similar between groups by 6 weeks when using multiple standardized outcome measures for assessment of pain. In addition, the low frequency of pain medication use may assist health care providers in appropriately prescribing pain medications and assessing patients postoperatively.

\section{REFERENCES}

1. Ward KL, Hilton P; UK and Ireland TVT Trial Group. Tension-free vaginal tape versus colposuspension for primary urodynamic stress incontinence: 5-year follow up. BJOG 2008;115:226-33.

2. Richter HE, Albo ME, Zyczynski HM, Kenton K, Norton PA, Sirls LT, et al. Retropubic versus transobturator midurethral slings for stress incontinence. N Engl J Med 2010;362: 2066-76.

3. Brubaker L, Norton PA, Albo ME, Chai TC, Dandreo KJ, Lloyd KL, et al. Adverse events over two years after retropubic or transobturator midurethral sling surgery: findings from the Trial of Midurethral Slings (TOMUS) study. Am J Obstet Gynecol 2011;205:498.e1-6. 
4. Ulmsten U, Henriksson L, Johnson P, Varhos G. An ambulatory surgical procedure under local anesthesia for treatment of female urinary incontinence. Int Urogynecol J Pelvic Floor Dysfunct 1996;7:81-5.

5. Delorme E. Transobturator urethral suspension: Mini-invasive procedure in the treatment of stress urinary incontinence in women [in French]. Prog Urol 2001;11:1306-13.

6. Ford AA, Rogerson L, Cody JD, Ogah J. Mid-urethral sling operations for stress urinary incontinence in women. The Cochrane Database of Systematic Reviews 2015, Issue 7. Art. No.: CD006375. DOI: 10.1002/14651858.CD006375. pub3.

7. Wang W, Zhu L, Lang J. Transobturator tape procedure versus tension-free vaginal tape for treatment of stress urinary incontinence. Int J Gynaecol Obstet 2009;104:113-6.

8. Lee KS, Han DH, Choi YS, Yum SH, Song SH, Doo CK, et al. A prospective trial comparing tension-free vaginal tape and transobturator vaginal tape inside-out for the surgical treatment of female stress urinary incontinence: 1-year followup. J Urol 2007;177:214-8.

9. Krofta L, Feyereisl J, Otcenásek M, Velebil P, Kasíková E, Krcmár M. TVT and TVT-O for surgical treatment of primary stress urinary incontinence: prospective randomized trial. Int Urogynecol J 2010;21:141-8.
10. Ross S, Robert M, Swaby C, Dederer L, Lier D, Tang S, et al. Transobturator tape compared with tension-free vaginal tape for stress incontinence: a randomized controlled trial. Obstet Gynecol 2009;114:1287-94.

11. Laurikainen E, Valpas A, Kivelä A, Kalliola T, Rinne K, Takala $\mathrm{T}$, et al. Retropubic compared with transobturator tape placement in treatment of urinary incontinence: a randomized controlled trial. Obstet Gynecol 2007;109:4-11.

12. Meschia M, Bertozzi R, Pifarotti P, Baccichet R, Bernasconi F, Guercio E, et al. Peri-operative morbidity and early results of a randomised trial comparing TVT and TVT-O. Int Urogynecol J Pelvic Floor Dysfunct 2007;18:1257-61.

13. Urinary Incontinence Treatment Network (UITN). The Trial of Mid-Urethral Slings (TOMUS): design and methodology. J Appl Res 2008;8. pii: AlboVol8No1.

14. Richter HE, Albo ME, Zyczynski HM, Kenton K, Norton PA, Sirls LT, et al. Retropubic versus transobturator midurethral slings for stress incontinence. Supplementary appendix. Available at: http://www.nejm.org/doi/suppl/10.1056/NEJMoa0912658/suppl_file/nejm_richter_2066sa1.pdf. Retrieved November 19, 2015.

15. McCarthy M Jr, Chang CH, Pickard AS, Giobbie-Hurder A, Price DD, Jonasson O, et al. Visual analog scales for assessing surgical pain. J Am Coll Surg 2005;201:245-52.

\section{Serve As a Reviewer for Obstetrics \& Gynecology}

The Editors of Obstetrics \& Gynecology are looking for new peer reviewers. Sign up to become a peer reviewer by going to http://ong.editorialmanager.com and downloading the "Reviewer Contact Information Update Form" (see "Files and Resources"). Please complete the form electronically and submit it by email to the editorial office (obgyn@greenjournal.org).

In recognition of their time, effort, and expertise, reviewers of manuscripts for Obstetrics \& Gynecology are eligible to receive continuing medical education credits.

Copyright $\odot$ by The American College of Obstetricians and Gynecologists. Published by Wolters Kluwer Health, Inc. Unauthorized reproduction of this article is prohibited. 